\title{
Diagnostic Performance of Visual Screening Tests in the Elderly
}

\author{
AIP Conf. Proc. -- September 14, 2011 -- Volume 1389, pp. 1553-1556 \\ NUMERICAL ANALYSIS AND APPLIED MATHEMATICS ICNAAM 2011; \\ doi:10.1063/1.3637925
}

Issue Date: 14 September 2011

Your access to this article is provided through the subscription of Inst Politecnico de Lisboa . ?

\section{Serviços $9^{\circ}$ on}

\section{ABSTRACT}

Carla Costa Lança $^{\mathrm{a}}$ and Elisabete Carolino ${ }^{\mathrm{b}}$

${ }^{a}$ Escola Superior de Tecnologia da Saúde de Lisboa (ESTeSL) -Instituto Politécnico de Lisboa / CIESP, Escola Nacional de Saúde Pública, UNL, Portugal

${ }^{b}$ ESTESL-IPL, Portugal

This study aimed to determine and evaluate the diagnostic accuracy of visual screening tests for detecting vision loss in elderly. This study is defined as study of diagnostic performance. The diagnostic accuracy of 5 visual tests -near convergence point, near accommodation point, stereopsis, contrast sensibility and amsler grid-was evaluated by means of the ROC method (receiver operating characteristics curves), sensitivity, specificity, positive and negative likelihood ratios $\left(L R^{+} / L R^{-}\right)$. Visual acuity was used as the reference standard. A sample of 44 elderly aged 76.7 years $( \pm 9.32)$, who were institutionalized, was collected. The curves of contrast sensitivity and stereopsis are the most accurate (area under the curves were 0.814-p $=0.001$, C.I.95\%[0.653;0.975]and $0.713-p=0.027$, C.I.95\% $[0,540 ; 0,887]$, respectively). The scores with the best diagnostic validity for the stereopsis test were 0.605 (sensitivity 0.87 , specificity 0.54 ; $L R^{+} 1.89, L R^{-} 0.24$ ) and 0.610 (sensitivity 0.81 , specificity $0.54 ; L R^{+} 1.75, L R^{-} 0.36$ ). The scores with higher diagnostic validity for the contrast sensibility test were 0.530 (sensitivity 0.94 , specificity $0.69 ; \mathrm{LR}^{+} 3.04, \mathrm{LR}^{-} 0.09$ ). The contrast sensitivity and stereopsis test's proved to be clinically useful in detecting vision loss in the elderly. (C)2011 American Institute of Physics

Permalink: $\underline{\text { http://link.aip.org/link/?APCPCS/1389/1553/1 }}$

Keywords

vision, vision defects, visual perception, information use

ISSN:

0094-243X (print) 